\title{
Low-cycle Fatigue Assessment of Offshore Mooring Chains Under Service Loading
}

\author{
G.M. Gemilang ${ }^{\text {a,b }}{ }^{*}$, P.A.S. Reed ${ }^{\text {c }}$, A.J. Sobey ${ }^{\text {a,d }}$ \\ a Maritime Engineering Group, University of Southampton, Boldrewood Innovation Campus, Southampton SO16 7QF, UK \\ Faculty of Infrastructure Planning, Department of Civil Engineering, Universitas Pertamina, Terusan Simprug, Jakarta, 12220, Indonesia \\ c \\ Engineering Materials Group, University of Southampton, Highfield, Southampton SO17 1BJ, UK \\ d Marine and Maritime Group, Data-centric Engineering, The Alan Turing Institute, The British Library, London, NW1 2DB, UK
}

\begin{abstract}
The integrity of mooring chains is essential to the safety of a range of offshore platforms. However, mooring line failures are occurring earlier than their design lives, with a high number of these failures occurring due to fatigue. Early in the fatigue life of the component fatigue initiation processes occur, where the fatigue hotspot is sensitive to the mean load and there is plastic strain accumulation from the multiaxial stress-strain responses of the material, leading to cyclic plastic damage accumulation. The traditional SN approach suggested by mooring standards does not consider these effects, and it is proposed that this lack of consideration under low-cycle fatigue conditions is the reason for the current non-conservative fatigue assessments of mooring chains. This paper aims to develop a fatigue approach based on a critical plane multiaxial fatigue criterion for mooring chains that can consider the damage-induced by the cyclic plasticity and the mean load effect, to investigate the importance of incorporating low-cycle fatigue into the mooring chain life prediction. To develop the critical plane approach, the multiaxial stress-strain states are extracted for the critical plane at the fatigue hotspot from a finite element model of a mooring chain. This is then correlated with a fatigue life prediction provided by conventional fatigue design data. It uses a simulation of an FPSO as a case study to demonstrate the importance of low cycle fatigue, which shows that the mean load effect is significant in reducing the fatigue life for mooring chain applications, while the effect of fatigue damage-induced cyclic plasticity is limited. The fatigue damage accumulation predicted by the critical plane approach is significantly higher than that of the traditional SN approach and should be accounted for in mooring line design.
\end{abstract}

Keywords: FPSO, Finite element method, Cyclic plasticity, Mean load effect, Fatigue damage, Low-cycle fatigue.

\section{Current design of mooring chains against fatigue}

There are many natural energy resources offshore, including oil, gas, wind and wave. As a result, floating offshore platforms are widely used for the exploitation of these energy sources [1] [2]. Continuous operation of floating offshore platforms relies on the integrity of mooring chains to keep these platforms in position against adverse environments over design lives of 20-years, or longer. However, mooring failures have occurred at a critically high rate in recent decades, with the potential for catastrophic financial and environmental impacts. Between 2000 and 2011, over 21 mooring failures occurred, of which about half occurred during the first three years [3] [4]; there were a further 16 failures on the Norwegian Continental Shelf between 2010-2014 [5], where these failures occurred in harsh sea environments. Several industry surveys [1] [3] [4] have identified multiple failure modes for the mooring lines of which fatigue failure is the most significant, requiring further investigations into why these predictions are non-conservative.

The traditional SN approach suggested by mooring standards, DNVGL-OS-E301 [6], is based on SN curves derived from full-scale fatigue tests on $76 \mathrm{~mm}$ chains of steel grades R3 and R4 under tensile loading at a constant mean load of $20 \%$ of the minimum breaking load in simulated seawater [6] [7] [8] [9]. This approach is stress-based, which is suitable for the high-cycle fatigue regime where plastic deformation is small or negligible but lacks an explicit consideration of the material's stress-strain evolution at the fatigue hotspot when determining the fatigue response. This approach does not consider the effects of mean load or cyclic plastic degradation of the material on the fatigue damage when subjected to low-cycle fatigue loading. However, since failure in service occurs earlier in their expected lives, it is proposed that the mooring chains are likely to have experienced a high proportion of low-cycle fatigue loading with high mean loads. The low-cycle fatigue regime is commonly considered to be better described by strain-life approaches, applied to lives of less than $10^{5}$ fatigue cycles, compared to the stress-life approaches for the high-cycle fatigue regime, $>10^{5}$ cycles [10]. Mooring

\footnotetext{
* Corresponding Author: gmg1g16@soton.ac.uk
} 
chains are subjected to approximately $5 \times 10^{6}$ fatigue cycles at three years of operation, assuming a $6 \mathrm{~s}$ period of loading cycles on average, showing that a high proportion of that damage occurs under low-cycle fatigue and this is likely be particularly significant when operating in harsh sea environments with high mean loads. The lack of consideration of mean load effects and cyclic plasticity effects for low-cycle fatigue is therefore proposed to be a contributing factor for the current non-conservative fatigue assessments of mooring chains.

In the mooring line literature, most published studies are limited to the stress-life approach which is suitable for the high-cycle fatigue regime, where plastic deformation is small or negligible [11] [12] [13] [14] [15] [16]. Although in some cases the stress-life approaches can predict the low-cycle fatigue behaviour [17] [18] [19] [20], they cannot reflect the constitutive behaviour of the material when the fatigue response changes from the high-cycle to low-cycle fatigue regime [19] [20] [21]. Therefore, the stress-life approach may underestimate the proportion of low-cycle fatigue in mooring line loading. The number of studies investigating low-cycle fatigue behaviour in mooring lines is limited, with only Zarandi and Skallerud [22] [23] using a strain-life approach to find the fatigue crack initiation life of corroded mooring chains. However, this is limited to deterministic cyclic loading, without considering the stochastic mooring line loading, and the addition of corrosion means it is difficult to isolate the effects of low-cycle fatigue on the mooring line failure.

Therefore, this paper aims to develop a fatigue approach capable of considering the mean load and cyclic plasticity effects on the fatigue damage which governs the low-cycle fatigue of mooring chains, to determine the importance of low-cycle fatigue in early failures currently observed in operating mooring lines. The analysis excludes other damage mechanisms (e.g. corrosion pitting), allowing for the isolation of the low-cycle fatigueinduced effects. The Smith-Watson-Topper approach using critical plane multiaxial fatigue criteria is selected since this approach has been demonstrated to accurately capture the mean load and cyclic plasticity effects in both high-cycle and low-cycle fatigue regimes, where fatigue damage is assessed directly in terms of local strains and stresses at the fatigue hotspot [21] [24] [25] [26] [27] [28] [29]. The fatigue damage accumulation predicted by this approach and that predicted by the traditional SN approach, are compared in a mooring line simulation of an FPSO, using the rainflow counting method and the Palmgren-Miner's rule.

\section{Development of a representative chain model}

A model of a mooring line is developed using the IACS [30] standardised dimensions for an offshore studless chain with a diameter, $D$. The total length, $L$, is equal to $6 D$; the total width, $W$, is $3.35 D$ and the curved section radius, $R$, is $0.675 D$, as illustrated in Fig. 1. The analysis is performed at two local hotspots, determined at the critical fatigue locations where the majority of fatigue failures have been found when under tension loading and are indicated in Fig. 1 as the Crown and $\mathrm{K}_{\mathrm{t}}$ points [8] [9] [31].

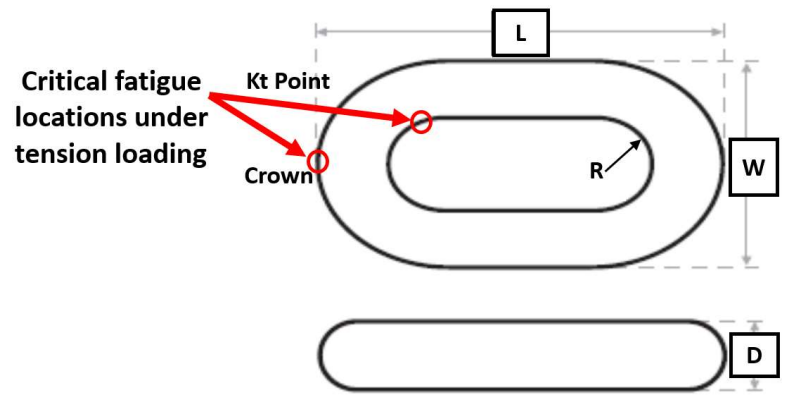

Fig. 1. The standardised dimensions for a studless chain, taken from IACS, and the critical fatigue locations.

The FE model is developed in ABAQUS 6.14 and automated using a Python script, considering both material and geometric nonlinearities using the explicit solver with C3D8R elements and a mass-scaling factor of 100, based on a previously developed method [32]. A $1 / 8^{\text {th }}$ portion of the chain is modelled that takes advantage of the three symmetry planes and minimises the computational cost, as shown in Fig. 2, where the slave model has a finer mesh as the resultant stresses and strains are extracted from these locations. The final mesh is defined using a convergence analysis which has a corresponding size of $3.5 \mathrm{~mm}$ for the slave model and $10 \mathrm{~mm}$ for the master model. Symmetric boundary conditions are applied to the symmetry planes shown in red in Fig. 2. The 
loaded surface at the top of the master model does not have this boundary condition, to allow the load to be applied in the axial direction. The symmetry boundary conditions constrain the displacement of nodes on each symmetry plane in the normal direction and the rotation in the other two directions. For example, the bottom surface of the slave model is constrained against displacement in the $\mathrm{y}$-axis and against rotation in the $\mathrm{x}$ and $\mathrm{z}$ axes. The contact discretisation is defined as surface-to-surface with a finite sliding formulation, as the tensiontension simulation assumes no sliding of one surface along with the other [33]. A friction coefficient of 0.7 is used for the tangential interaction behaviour [12].

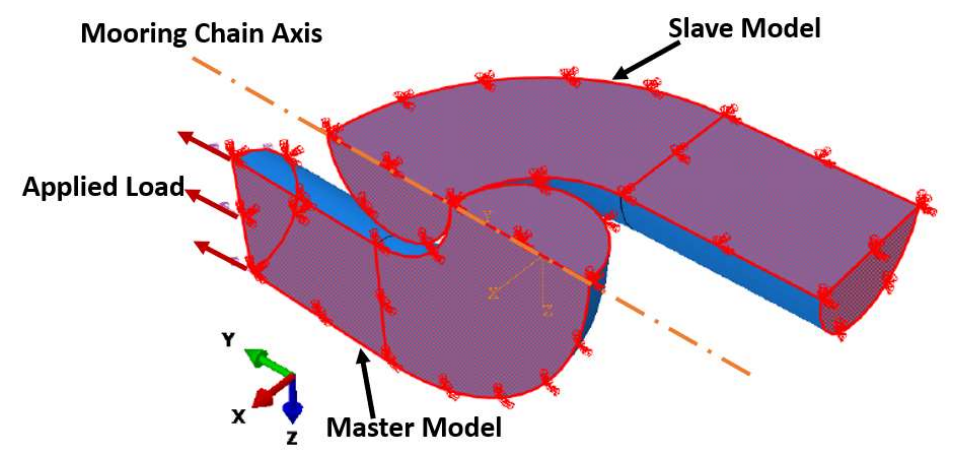

Fig. 2. The finite element model of the chain-link where the left part is the master and the right part is the slave.

\section{Material models}

In order to determine how the material selection affects the fatigue predictions, material models representative of the monotonic and cyclic mechanical properties are considered, and a comparison is made between them. The R4 steel grade is considered, as it is the most prevalent material grade currently in use for mooring chains [8]. A monotonic material model is developed from mechanical properties derived from tensile tests conducted by Rampi et al. [34], in which a bilinear isotropic hardening is used, and the strain associated with the tensile strength is adopted as half the total elongation specified in the standards [14] [35], this is designated MonoRampi. Two models are developed to describe the cyclic material responses, which are derived from low-cycle fatigue tests conducted by Rampi et al. [34], designated Cyclic-Rampi, and Zarandi and Skallerud [22], designated Cyclic-Zarandi, using the constitutive model of the combined nonlinear isotropic-kinematic hardening proposed by Chaboche [36]. This constitutive model has been widely used in modelling fatigue and has been shown to be robust in describing the mechanical properties of a material under cyclic loading [36] [37]. Table 1 outlines the material properties with a Young's modulus, $E$, of $206.6 \mathrm{GPa}$ and a Poisson's ratio, $v$, of 0.3 for each model, where $\sigma_{\mathrm{y}}$ is the monotonic yield strength, $\sigma_{\mathrm{T}}$ is the monotonic tensile strength, $A_{\mathrm{T}}$ is total elongation, $\left.\sigma\right|_{0}$ is the yield strength at zero plastic strain, $Q_{\infty}$ is the maximum change in yield strength, $b$ is the rate at which the yield surface changes with the development of plastic strain accumulation, $C$ is the initial kinematic hardening moduli, and $\gamma$ determines the decreasing rate of the kinematic hardening moduli with increasing plastic strain accumulation.

Table 1 Parameters for the monotonic and cyclic material models.

\begin{tabular}{|c|c|c|c|c|c|c|}
\hline \multirow{2}{*}{$\begin{array}{c}\text { Monotonic } \\
\text { material model }\end{array}$} & \multirow{2}{*}{ Ref. } & Yield strength & \multicolumn{2}{|c|}{ Tensile strength } & \multicolumn{2}{|c|}{ Total elongation } \\
\hline & & $\sigma_{\mathrm{y}}(\mathrm{MPa})$ & \multicolumn{2}{|c|}{$\sigma_{\mathrm{T}}(\mathrm{MPa})$} & \multicolumn{2}{|c|}{$A_{\mathrm{T}}(\%)$} \\
\hline Mono-Rampi & {$[34]$} & 903 & \multicolumn{2}{|c|}{1039} & \multicolumn{2}{|c|}{12} \\
\hline \multirow{2}{*}{$\begin{array}{l}\text { Cyclic material } \\
\text { model }\end{array}$} & \multirow{2}{*}{ Ref. } & Initial yield strength & \multicolumn{2}{|c|}{ Isotropic component } & \multicolumn{2}{|c|}{ Kinematic component } \\
\hline & & $\left.\sigma\right|_{0}(\mathrm{MPa})$ & $Q_{\infty}(\mathrm{MPa})$ & $b$ & $C$ & $\gamma$ \\
\hline Cyclic-Rampi & {$[34]$} & 723.6 & -141.6 & 1.42 & 244100 & 1379 \\
\hline Cyclic-Zarandi & {$[22]$} & 546 & -227 & 3.1 & 536565 & 1500 \\
\hline
\end{tabular}

Fig. 3 demonstrates the material models in ABAQUS using a single element model under displacement control to show their differences in describing the material response under monotonic loading and cyclic loading 
conditions. Fig. 3(a) shows the materials' stress-strain curves under monotonic loading, where Cyclic-Rampi and Cyclic-Zarandi exhibit similar plastic responses. For these models, the stresses decrease with increases in plastic strain due to the materials' cyclic softening response. However, the curve of the Mono-Rampi increases linearly from the yield stress to the tensile stress but remains constant when the plastic strain is above the tensile strength, without any cyclic softening. The Mono-Rampi properties were selected to determine the difference in life predictions between monotonic or cyclic material models as the amount of plastic strain will be underestimated, in comparison to the cyclic material models, when subjected to monotonic loading. These differences will lead to variations in the initial elastic shakedown for the first cycle, the state where the stress-strain relationship is stabilised in elastic behaviour [10].

Fig. 3(b) shows the material responses under cyclic loading, where cyclic loading is selected to show the evolution of the maximum and minimum values of the peak stresses using the number of cycles experienced by the material models at a strain range, $\Delta \varepsilon$, of 0.0155 and a strain ratio, $R_{\varepsilon}$, of -1 . Under this cyclic loading, the Cyclic-Rampi and Cyclic-Zarandi models exhibit cyclic softening behaviour in the early cycles, which then develops more slowly during the subsequent cycles until stabilisation of the elastic shakedown is achieved. Cyclic-Zarandi has a more significant cyclic softening behaviour, leading to a higher amount of plastic strain than Cyclic-Rampi. This is because the Cyclic-Zarandi is derived from low-cycle fatigue tests at a higher strain range than the one used to obtain Cyclic-Rampi, resulting in a more significant cyclic softening response [22] [34]. However, the Mono-Rampi is unable to simulate the cyclic softening behaviour, instead exhibiting hardening behaviour in the first five cycles, and develops elastic shakedown before the cyclic material models. Therefore, the Mono-Rampi will develop the highest values of peak stress throughout the cycles. This implies that the use of the monotonic material models will significantly underestimate the amount of plastic strain and the cyclic plasticity effects in applications where the components are experiencing cyclic stress-strain evolution under progressive loading cycles, which may lead to inaccurate fatigue life estimations.
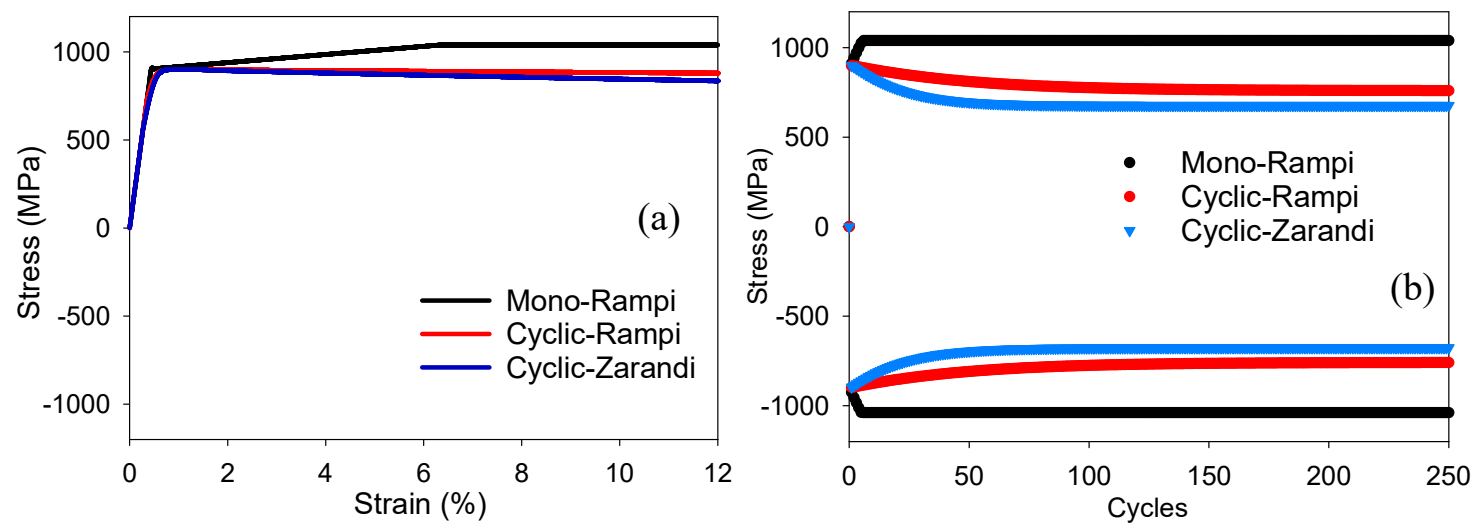

Fig. 3. Comparison between each material model (a) under monotonic loading, showing the stress-strain curves (b) under cyclic loading, showing the evolution of the maximum and minimum values of the peak stresses with the number of cycles.

\section{Calibration of the critical plane fatigue assessment}

Smith et al. [38] [39] proposed a critical plane multiaxial fatigue method, where fatigue damage is assessed directly in terms of local strains and stresses under progressive loading cycles. The method is described by Eq. (1),

$$
S W T=\sigma_{\mathrm{n}, \max } \frac{\Delta \varepsilon_{\mathrm{n}}}{2}
$$

where $S W T$ is the damage parameter, $\sigma_{\mathrm{n}, \max }$ is the maximum normal stress and $\Delta \varepsilon_{\mathrm{n}}$ is the normal strain range perpendicular to the critical plane during one cycle. The $S W T$ damage parameter represents the real physical properties of the stress-strain function at the critical fatigue location, that has been demonstrated governing the 
fatigue of metal structures [38]. The critical plane is determined by checking the value of $S W T$ on different planes in a stabilised cyclic load, where the plane with the highest $S W T$ is defined as the critical plane. The $S W T$ damage parameter can be related with fatigue life using a general formula given in Eq. (2),

$$
S W T=A_{1} N_{\mathrm{f}}^{a_{1}}+A_{2} N_{\mathrm{f}}^{a_{2}},
$$

where $N_{\mathrm{f}}$ is the number of cycles to failure, $A 1, A_{2}, a_{1}$ and $a_{2}$ are material constants and can be determined by calibration tests from experimental data. This general formula is used to generate a fitted curve for $S W T$ damage parameters across a range of the number of cycles to failure. This method is based on the assumption that the surface of the part is intact without considering the effects of varying surface roughness, or pre-existing defects. This assumption can be considered to be reasonable as the chain is inspected to ensure that there are no visible surface defects prior to deployment. Therefore, in conditions where pre-existing defects do not significantly accelerate crack initiation and early propagation stages, acceptable life prediction results can be expected using this fatigue method as long as the macroscopic stress/strain evolutions at critical regions during fatigue loading are accurately determined so that the overall damage accumulation in the component is reasonably predicted.

DNVGL-OS-E301 [6] provides the number of cycles to failure of mooring chains under different loading conditions providing fatigue design data based on SN curves derived from full-scale fatigue tests. The full-scale fatigue tests are simulated in our FE model to establish the SWT damage parameters correlated to the fatigue life data based on the conventional design data adopted from DNVGL-OS-E301 [6] at different load amplitudes. The tests subject a chain with a diameter of $76 \mathrm{~mm}$, and made from R4 steel grade, to a first proof load cycle up to $70 \%$ of the minimum breaking load and then back to zero. This is followed by cyclic loads with a constant mean load equal to $20 \%$ of the minimum breaking load, but under a different load amplitude for each test [6] [7] [8] [9]. The minimum breaking load is $6001 \mathrm{kN}$ for this chain type according to the standard, IACS-W22 [30]. The proof load results in significant plastic deformation and compressive residual stresses developing at both the fatigue hotspots, the crown and $\mathrm{K}_{\mathrm{t}}$ point. The stabilised stress-strain response better describes the subsequent fatigue behaviour [18] [26], and therefore the cyclic loads are run until the stress-strain response is stabilised under elastic shakedown, where the maximum normal stress, $\sigma_{\mathrm{n}, \max }$, and the normal strain range, $\Delta \varepsilon_{\mathrm{n}}$, on the critical plane are extracted from the FE results to calculate the $S W T$ damage parameters, according to Eq. (2).

To determine the critical plane, the $S W T$ value is checked in the stabilised cyclic load state for all planes between $-90^{\circ}<\varphi<90^{\circ}$ measured counter-clockwise from the longitudinal direction to the normal vector with an interval of $1^{\circ}$, where the plane with the highest $S W T$ value is taken as the critical plane. Fig. 4(a) shows an example where the resultant $S W T$ damage parameters on different planes for both crown and $\mathrm{K}_{\mathrm{t}}$ point under a load amplitude of $11 \% \mathrm{MBL}$ are shown, indicating that the maximum damage parameter is reached when $\varphi=0^{\circ}$, this is then defined as the critical plane and is used to calculate the $S W T$ damage parameter for this particular fatigue loading case. Fig. 4(b) shows the damage parameters on the critical plane of the $\mathrm{K}_{\mathrm{t}}$ point are lower than those of the crown with a mean absolute difference of 0.0352 and a maximum absolute difference of 0.049 , across the range of selected load amplitudes. The result is in line with full-scale experimental fatigue results [8] [9] [40], where the crown is found to be more susceptible to fatigue damage than the $K_{t}$ point. This is because the $K_{t}$ point has higher residual compressive stresses than at the crown upon release of the proof load. Subsequent analyses, therefore, concentrate on the crown for the fatigue assessments. The results presented in Fig. 4 use the CyclicRampi material model, but similar results were found using the other material models. Fig. 4(b) also shows that the $S W T$ damage parameter is near zero when the load amplitude is relatively low. This is because the critical plane approach assumes no fatigue damage occurs when the maximum normal stress perpendicular to the critical plane is compressive, and the compressive stresses have been induced by previous proof load applications. 

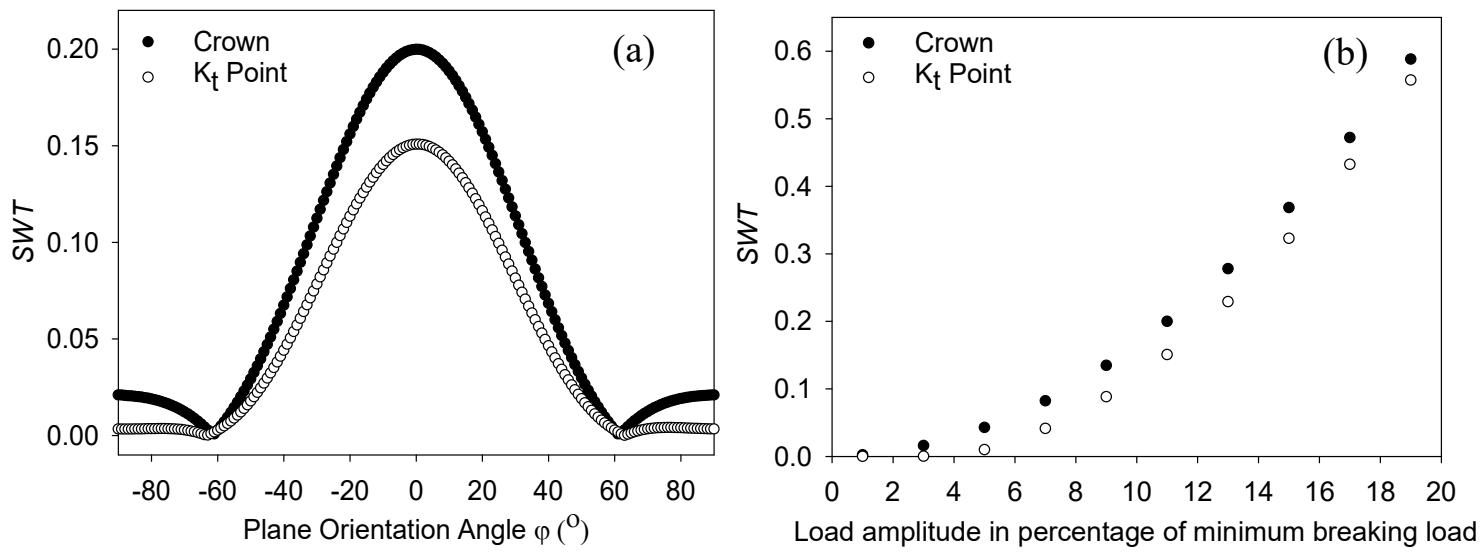

Fig. 4. Comparison between the crown and $\mathrm{K}_{\mathrm{t}}$ point (a) damage parameters on different plane orientation angles, (b) damage parameters on the critical plane under a range of load amplitudes.

The maximum normal stress, $\sigma_{\mathrm{n} \text {,max }}$, and the normal strain range, $\Delta \varepsilon_{\mathrm{n}}$, on the critical plane at the crown hotspot during the stabilised cyclic load are therefore used to calculate the $S W T$ damage parameters, according to Eq. (1). The SWT damage parameters are correlated with the respective number of cycles to failure from the fatigue life predictions of DNVGL-OS-E301 [6] by simulating the fatigue tests under different loading conditions, which are a constant mean load of $20 \% \mathrm{MBL}$ and various load amplitudes, i.e. from $1 \%$ to $19 \% \mathrm{MBL}$, based on mooring chains service lives.

The resultant $S W T$ damage parameters, under different load amplitudes, are used to calibrate the parameters of the fitted curves based on the general formula of Eq. (2) in order to interpolate the number of cycles to failure from the corresponding $S W T$ damage parameters during fatigue loading. Fig. 5 shows the generated fitted curves, using the resultant $S W T$ damage parameters, across a range of the number of cycles to failure. Appendix A provides the details of SWT damage parameters under different load amplitudes and the calibration of the fitted curves. Cyclic-Rampi and Cyclic Zarandi have similar curves as both exhibit cyclic softening during the first cycle, while the curve of the Mono-Rampi increases to a higher value than the others. This is because of the significant hardening behaviour of Mono-Rampi during the first cycle results in a high maximum normal stress, $\sigma_{\mathrm{n}, \max }$. Unlike the traditional SN approach, the critical plane approach takes all of the local stress-strain evolution into account when determining the fatigue response, including the proof load-induced effects i.e. strain hardening and residual stresses, mean load effects, material model nonlinearities and geometric nonlinearities. The FE-based critical plane approach has been correlated with the fatigue design data adopted from DNVGLOS-E301 [6], allowing the fatigue life to be predicted by a fitted curve for a particular material model.

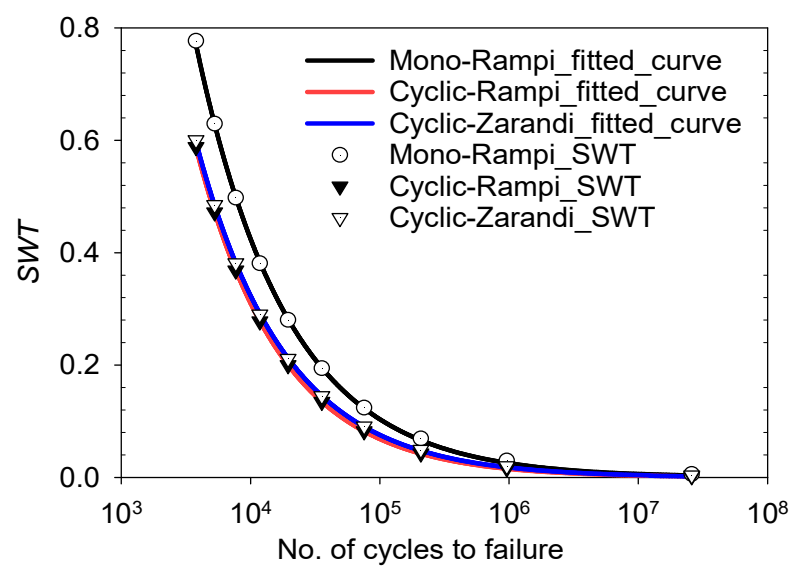

Fig. 5. The fitted calibration curves based on the fatigue life of mooring chains for the Smith-Watson-Topper (SWT) using the stress/strain data at the crown fatigue hotspot for the different material models. 


\section{Fatigue simulations}

\subsection{Mooring chain loading}

In order to simulate the fatigue experienced by the mooring chains in service, the tension-spectrum, representing the fatigue loading, is simulated in a mooring line simulation of an FPSO as a case study using the Flexcom package [41]. The case study simulates a mooring system of an FPSO at a water depth of $810 \mathrm{~m}$ in a specific seastate adopted from Gao and Moan [42] for short-term analysis. The sea-state is characterised by the significant wave height, $H_{\mathrm{s}}=6.25 \mathrm{~m}$, a spectral peak period, $T_{\mathrm{p}}=12.5 \mathrm{~s}$, a 1 -hour mean wind velocity, $U_{\mathrm{w}}=7.5 \mathrm{~m} / \mathrm{s}$, and a mean current velocity, $U_{\mathrm{c}}=0.5 \mathrm{~m} / \mathrm{s}$, where the Pierson-Moskowitz wave spectrum is applied, and all environmental loads are assumed to act from the head sea. The main particulars of the FPSO are adopted from the Flexcom package [41], which are listed in Table 2. The RAO and QTF are taken from the Flexcom package [41] to include the first-order and second-order motions of the FPSO to give the combined vessel response.

Table 2 Main particulars of the FPSO taken from Flexcom.

\begin{tabular}{ll}
\hline Parameter & Value \\
\hline Vessel mass & $382,734 \mathrm{t}$ \\
Vessel draft & $21.2 \mathrm{~m}$ \\
Vessel beam & $58.2 \mathrm{~m}$ \\
Length from COG to forward perpendicular & $162.5 \mathrm{~m}$ \\
Length from COG to aft perpendicular & $176.7 \mathrm{~m}$ \\
Length from COG to turret point & $150 \mathrm{~m}$ \\
\hline
\end{tabular}

The mooring system is an eight-line catenary system with chain-wire rope-chain components connected to a turret of the FPSO with a pre-tension of $1037 \mathrm{kN}(17 \% \mathrm{MBL})$ for each line. Table 3 shows the mooring component principals, which are adopted from the Flexcom package [41].

Table 3 Mooring component principals.

\begin{tabular}{ccccccc}
\hline Parameter & $\begin{array}{c}\text { Length } \\
(\mathrm{m})\end{array}$ & $\begin{array}{c}\text { Size } \\
(\mathrm{mm})\end{array}$ & $\begin{array}{c}\text { Mass per meter } \\
(\mathrm{kg} / \mathrm{m})\end{array}$ & $\begin{array}{c}\text { Axial stiffness } \\
(\mathrm{kN})\end{array}$ & $\begin{array}{c}\text { Normal drag } \\
\text { coeff. }\end{array}$ & $\begin{array}{c}\text { Longitudinal } \\
\text { drag coeff. }\end{array}$ \\
\hline Anchor chain & 500 & 76 & 115 & $4.935 \times 10^{5}$ & 2.4 & 1.15 \\
Wire rope & 400 & 89 & 62 & $7.03 \times 10^{5}$ & 1.2 & 0.1 \\
Top chain & 200 & 76 & 115 & $4.935 \times 10^{5}$ & 2.4 & 1.15 \\
\hline
\end{tabular}

Fig. 6 shows the horizontal projection of the mooring system with an angular spread of $45^{\circ}$ between the lines. The anchor radius from the turret centreline is $700 \mathrm{~m}$, with which the mooring line anchor points are constrained, and each fairlead is attached to the FPSO via hinges at $8 \mathrm{~m}$ below the mean water level. A time-domain simulation of 3 hours is used, as suggested by the mooring standard DNVGL-OS-E301 [6], to provide adequate statistics with a time step of $0.1 \mathrm{~s}$. The effect of the system's nonlinear characteristics is included through both the wave-frequency and the low-frequency tension spectra through coupled dynamic analysis. The top chain experiencing the greatest tensions is analysed, and the tension-spectrum of the top chain is used for fatigue analysis, as suggested by the mooring standard, API-RP-2SK [43]. 


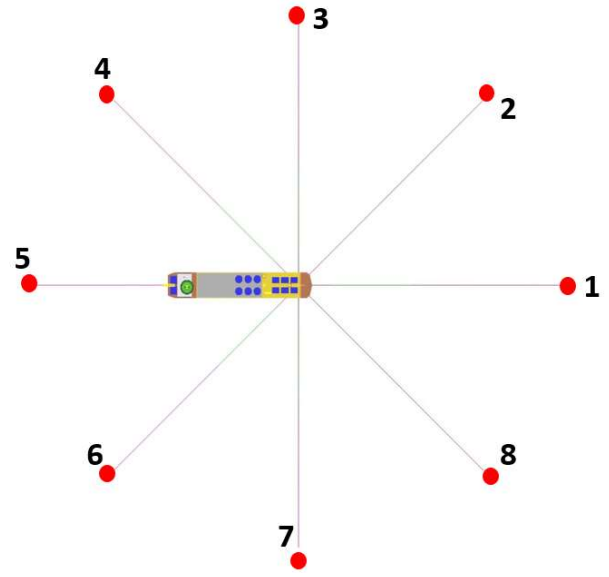

Fig. 6. Mooring system arrangement in this simulation taken from Flexcom [41].

\subsection{Fatigue Damage Comparison}

The tension-spectrum from the mooring line simulation consists of combined high-cycle and low-cycle fatigue loading with a maximum tension of $2595 \mathrm{kN}$, a mean of $1272 \mathrm{kN}$ and a minimum of $617 \mathrm{kN}$. The rainflow counting method [44] is used to identify individual loading cycles within the tension-spectrum because it has been shown to give reasonable fatigue estimates [45]. The total fatigue damage is calculated using the PalmgrenMiner's rule [46], assuming that the total fatigue damage caused by a number of stress cycles equals the summation of damages caused by the individual loading cycles. The individual loading cycles from the tensionspectrum is simulated in the FE chain model after which the proof load, and its release, are applied to simulate the mooring chains' loading history. The fatigue damage accumulation is predicted using the Smith-WatsonTopper critical plane approach and the traditional SN approach to allow a comparison between these two approaches.

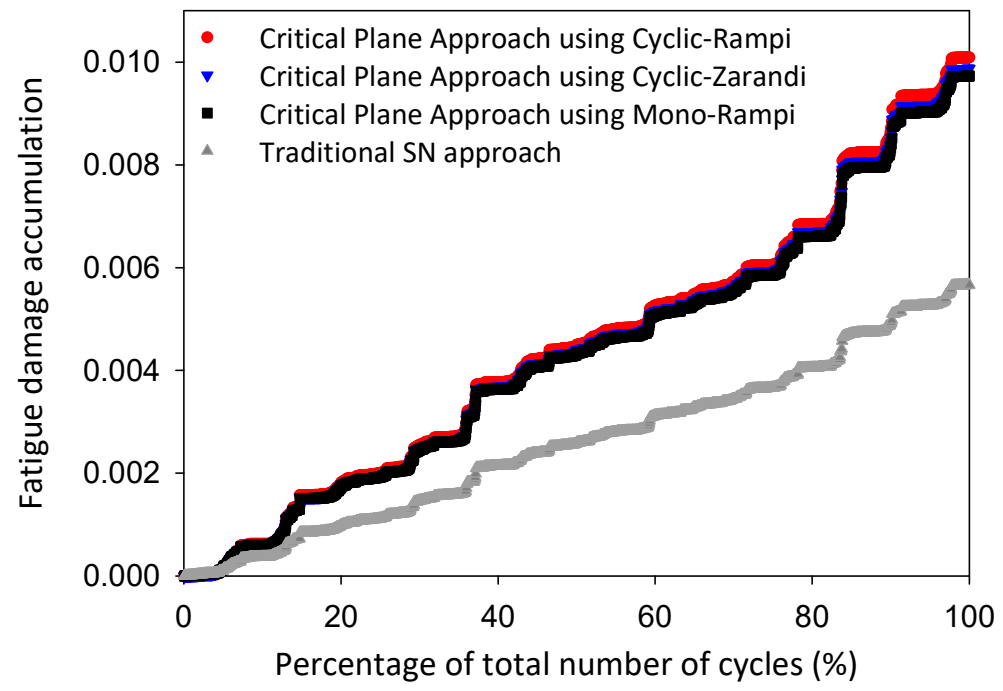

Fig. 7. Comparison of the predicted fatigue damage accumulation using different approaches.

Fig. 7 shows that the predicted fatigue damage accumulation of the critical plane approach is significantly higher than that of the traditional SN approach. The different material models used in the critical plane approach all predict a significantly higher fatigue damage accumulation relative to the traditional SN approach, by $78.1 \%$ using Cyclic-Rampi, 74.3\% using Cyclic-Zarandi and 71.74\% using Mono-Rampi. On average, the traditional 
SN approach predicts $7.2 \%$ of all the individual loading cycles will contribute to low-cycle fatigue, while the critical plane approach predicts $12.9 \%$ will, across all the material models considered. This indicates that the critical plane approach captures a greater number of important low-cycle fatigue events in the mooring line loading because it accounts for the effects of the mean load and cyclic plasticity in the fatigue life assessment.

Fig. 8 shows the ratio between the fatigue damage predicted by the critical plane approach and that predicted by the traditional SN approach over a range of mean loads and load amplitudes, using Cyclic-Rampi and MonoRampi material models as these represent the maximum and minimum predictions from the critical plane approach in the case study. The mean load effect changes at $20 \% \mathrm{MBL}$, showing that the lower the load amplitude, the higher the fatigue damage ratio when the mean load level is above $20 \% \mathrm{MBL}$, while the opposite happens when the mean load level is below $20 \%$ MBL. The fatigue damage ratio is one at the mean load of $20 \%$ MBL, since the critical plane approach is calibrated based on the same fatigue design data as the traditional approach at this mean load level, obtained from DNVGL-OS-E301[6]. At higher mean loads, the fatigue damage prediction is higher for the critical plane approach than the traditional SN approach, resulting in the difference between the two methods being more significant even if the stresses at the hotspot are smaller than the elastic limit, and this becomes more significant with lower load amplitudes.
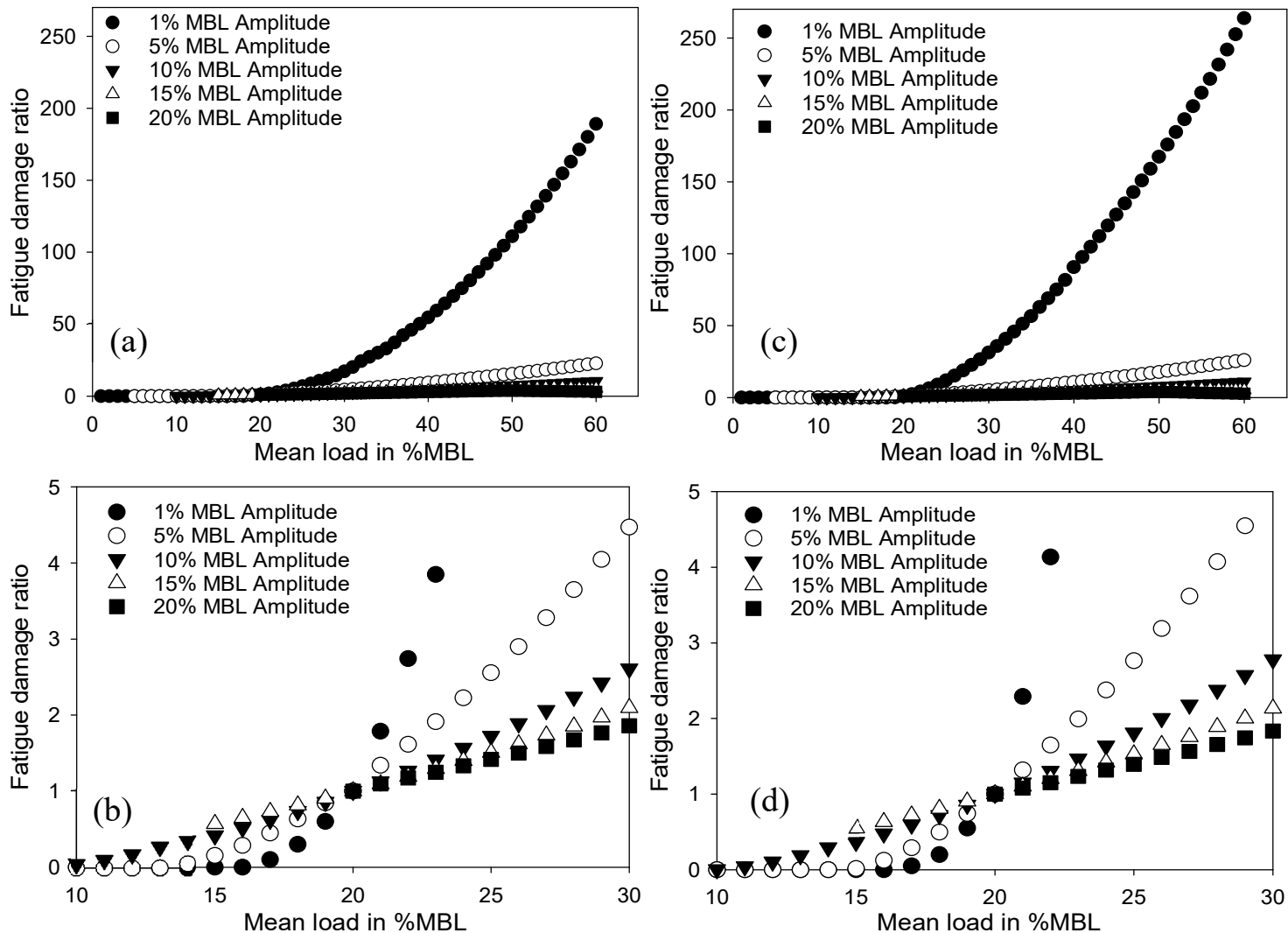

Fig. 8. Mean load effects on the fatigue damage ratio in a range of mean load for Mono-Rampi (a) full range of MBLs $0-60 \%$ (b) change in behaviour due to the amplitude at a mean load of $20 \% \mathrm{MBL}$, and for Cyclic-Rampi

(c) full range of MBLs $0-60 \%$ (d) change in behaviour due to the amplitude at a mean load of $20 \% \mathrm{MBL}$.

These mean load effects are reflected in the accumulated fatigue damage comparison shown in Fig. 7, where about half of all the individual load cycles in the tension-spectrum have mean loads above $20 \%$ MBL and load amplitudes mostly ranged from $0 \%$ to $5 \% \mathrm{MBL}$. The fatigue damage ratios of the Cyclic-Rampi are higher than the fatigue ratios of the Mono-Rampi, explaining the increase in fatigue damage accumulation for the CyclicRampi model compared to that for the Mono-Rampi. Although the Mono-Rampi cannot predict the cyclic softening behaviour, the strain hardening effect due to the proof load during the first cycle maintains the stress- 
strain response in the elastic shakedown with no clear plastic deformation beyond the first cycle, meaning that the cyclic plasticity effects are not evident during fatigue loading in the case study. Therefore, the results of Mono-Rampi and Cyclic-Rampi are similar.

In order to investigate the cyclic plasticity effect, Fig. 9(a) and Fig. 9(b) show the stress-strain responses and equivalent plastic strain, respectively, when the proof load is applied, released, and followed by cyclic loads with an amplitude of $20 \% \mathrm{MBL}$ in an incremental mean load with an interval of $1 \% \mathrm{MBL}$ for each progressive cycle. The cyclic stress-strain evolution and the plastic strain accumulation starts to occur at a mean load of $50 \% \mathrm{MBL}$, meaning that cyclic plasticity starts to take effect when the cyclic load reaches the proof load level. In contrast, the cyclic plasticity does not take effect when the cyclic load is below 70\% MBL. This is because strain hardening, due to the proof load on the first cycle, has a significant effect on maintaining the stress-strain response in elastic shakedown throughout all cycles that are below $70 \% \mathrm{MBL}$. Therefore, the cyclic plasticity effect is minor in the case study for all material models since the individual loading cycles within the tensionspectrum are below 70\% MBL. The Mono-Rampi model underestimates the amount of cumulative plastic straining with a mean difference of $28 \%$ relative to the Cyclic-Rampi model since the monotonic material model cannot predict the cyclic-softening behaviour, leading to an inaccurate estimation of the fatigue life when cyclic plasticity is involved during fatigue loading in service.
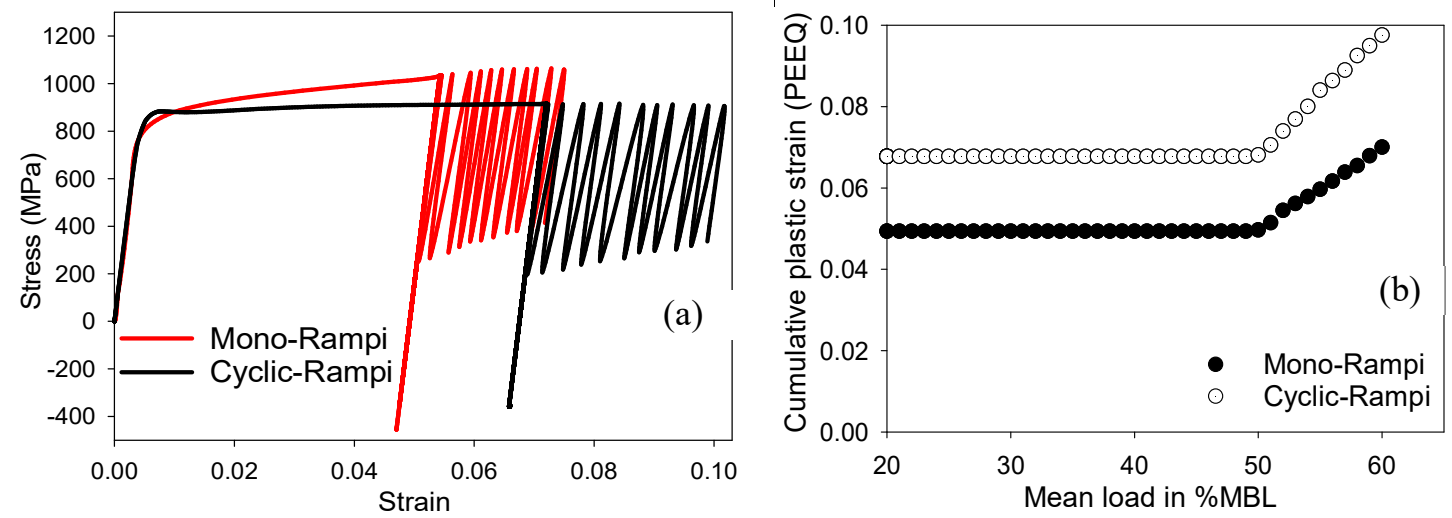

Fig. 9. Fatigue simulation when the proof load is applied, released, and followed by cyclic loads with an amplitude of $20 \% \mathrm{MBL}$ in an incremental mean load with an interval of $1 \% \mathrm{MBL}$ for each progressive cycle, showing (a) the stress-strain responses, (b) the plastic strain accumulation.

\subsection{Parametric study for fatigue in different sea-states}

Since the mean load is shown to have a significant effect, a parametric study for fatigue in different sea-states is used to assess how often the mean load is above $20 \% \mathrm{MBL}$, to identify when the critical plane approach is of significance and to understand the importance of the mean load on fatigue life. The variation of waves over the long-term environment can be described by several representative sea-states, against which the fatigue damage is weighted using the lumped occurrence probability, the proportion of occurrences of a representative sea-state out of the total probability for all sea-states. A typical scatter diagram in the North Sea, consisting of 197 original sea-states, is adopted from Song and Wang [47] which uses the JONSWAP wave spectrum to define the significant wave height, $H_{\mathrm{s}}$, and up-crossing wave period, $T_{\mathrm{z}}$. The scatter diagram is partitioned into nine representative sea-state blocks at which the coupled dynamic analysis is simulated for this parametric study, as presented in Appendix B. Only the wave loads are changed in the representative sea-states, while the other assumptions and parameters remain the same as the previous case study described in section 5.1. Table 4 shows the selected representative sea-state blocks based on the highest occurrence rate within each block, with the respective lumped occurrence probability, $p$. 
Table 4 The wave parameters for the nine representative partitions of the North Sea.

\begin{tabular}{cccc} 
No. & $H_{\mathrm{s}}(\mathrm{m})$ & $T_{\mathrm{z}}(\mathrm{s})$ & $p(\%)$ \\
\hline 1 & 1.5 & 7.5 & 47.976 \\
2 & 2.5 & 10.5 & 20.588 \\
3 & 5.5 & 8.5 & 15.356 \\
4 & 4.5 & 11.5 & 11.067 \\
5 & 7.5 & 9.5 & 2.643 \\
6 & 8.5 & 12.5 & 1.878 \\
7 & 11.5 & 10.5 & 0.167 \\
8 & 10.5 & 12.5 & 0.292 \\
9 & 13.5 & 11.5 & 0.032 \\
\hline
\end{tabular}

Fig. 10 shows the mean load distribution in the individual loading cycles of tension-spectrum for each sea-state, separating mean loads at greater than 20\% MBL. Sea-states 1, 2, and 3 in Fig. 10(a) are benign, having respectively $0 \%, 0.3 \%$ and $5.3 \%$ of the mean load proportion above $20 \% \mathrm{MBL}$; therefore, the traditional SN approach can be used. However, sea-states 4, 5 and 6 in Fig. 10(b) have respectively $21.4 \%, 33.5 \%$ and $36.3 \%$ of the mean load proportion above 20\% MBL, and sea-states 7, 8 and 9 in Fig. 10(c) have respectively 42.4\%, 44\% and $46.3 \%$ of the mean load proportion above $20 \%$ MBL. At these higher sea-states, it is important to consider the detrimental effect of the mean load on the fatigue assessment by using the critical plane approach. Similarly, the first case study also has about half of the mean load proportion above $20 \%$ MBL. However, the load-amplitude proportions above $5 \% \mathrm{MBL}$, that can cause the number of cycles to failure below $10^{5}$ in the low-cycle fatigue regime, are $15.8 \%, 19.4 \%, 34.7 \%$ for the sea-states $7-9$, respectively, while this is $12.9 \%$ for the first case study. This shows that in conditions with higher proportions of severe sea-states, the higher the proportion of time the mean load is above $20 \% \mathrm{MBL}$ and the more important the critical plane approach becomes.

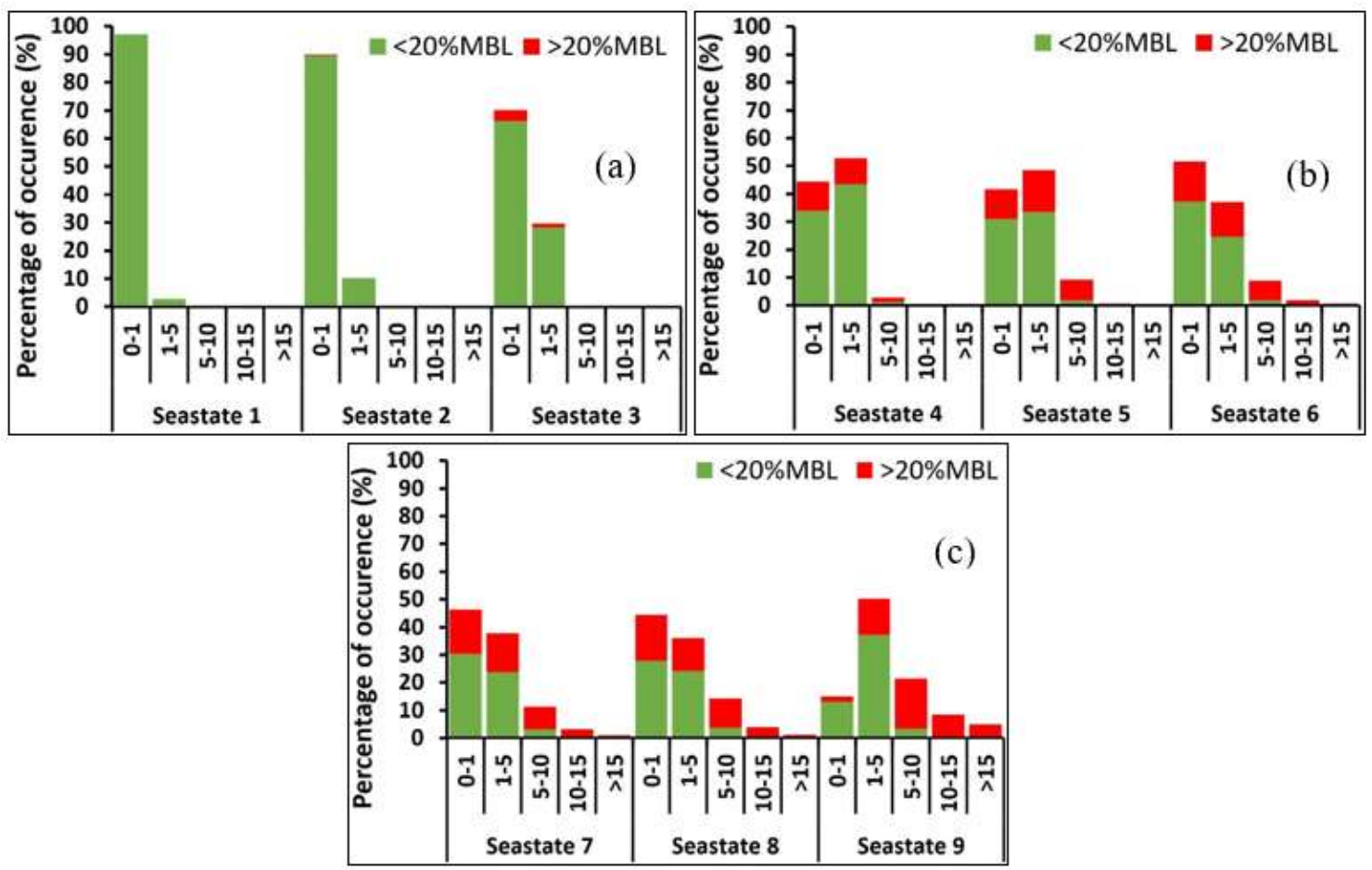

Fig. 10. Mean load distribution in the individual loading cycles of tension-spectrum for (a) sea-states 1-3 (b) seastates 4-6 (c) sea-states 7-9, where the horizontal axis denotes ranges of load amplitudes in the percentage of the 
minimum breaking load ( $\% \mathrm{MBL}$ ), and the green represents mean load below $20 \% \mathrm{MBL}$, and the red represents mean load above $20 \%$ MBL.

\section{Discussion}

The fatigue damage accumulation of the critical plane approach is significantly higher relative to the traditional SN approach; $74.7 \%$ on average for all of the material models used in the case study. This is mainly because the mean load effects are incorporated in the critical plane approach. No cyclic plasticity occurs as the mechanisms are only applied when the tension load exceeds $70 \%$ MBL due to the strain hardening effect from the proof load during the first cycle, and therefore the assumption of the Palmgren-Miner's rule can be applied, although the Palmgren-Miner's rule does not account for any load sequence effects [46]. The mean load effect of the critical plane approach shows that fatigue life decreases with an increase in mean load. This is in agreement with fullscale tests in the recent literature [7] [9], which found that the fatigue life decreases by a factor of 5-10 as the mean load increases from $6.4 \% \mathrm{MBL}$ to $20 \% \mathrm{MBL}$ and found that the fatigue life decreases by a factor of 4 as the mean load increases from $10 \%$ MBL to $20 \%$ MBL.

When using the standard SN approach, common industry practices suggest using a safety factor of 3 for regularly inspected components and that this safety factor can be increased up to 10 for non-inspected components [6] [43]. However, the critical plane approach suggests that these suggested safety factors may be insufficient, indicating that the fatigue life in mooring chain failures can be overpredicted when using the traditional SN approach by factors higher than the suggested safety factors in some cases. The factors are quantified in terms of the fatigue damage ratio in Fig. 8, showing that the higher the mean load, the larger the separation in fatigue damage prediction between the critical plane approach and the traditional SN approach; this can be many times larger when the mean load is above $20 \% \mathrm{MBL}$, depending on the mean load and the load amplitude levels. A feature of this critical plane approach is that it predicts lower fatigue damage than the traditional SN approach when the mean load is below $20 \% \mathrm{MBL}$, and the difference because of this depends on the load amplitude and the mean load as demonstrated in Fig. 8. This is because the critical plane approach accounts for the compressive residual stress from the proof load during the first cycle.

To show the difference in low-cycle fatigue prediction between both approaches, Fig. 11 shows the demarcation between low-cycle and high-cycle fatigue loading, at the lifetime of $10^{5}$ cycles, predicted by using the different approaches, where the region above each line represents the low-cycle fatigue regime and the region below it indicates the high-cycle fatigue regime. The lines are generated by calculating at which load amplitude level the respective fatigue approach predicts the lifetime of $10^{5}$ cycles across different mean load levels. The traditional

SN approach shows this demarcation as a straight line at a load amplitude of just over $6 \%$ MBL since it does not consider the mean load effects, while the critical plane approach shows this demarcation as a curve where the higher the mean load, the lower load amplitude to reach the low-cycle fatigue regime. The region on the lefthand side is where the mean load is below $20 \% \mathrm{MBL}$ and illustrates the conservativeness of the traditional SN approach as it predicts low-cycle fatigue at lower amplitude. However, on the right-hand side, the critical plane approach is more conservative from the mean load level of $20 \% \mathrm{MBL}$ onwards, predicting low-cycle fatigue at increasingly lower amplitudes and showing a larger proportion of low-cycle fatigue for a given sea-state. The more conservative prediction of the critical plane approach is reflected in the previous case study since about half of the individual loading cycles have mean load levels above $20 \% \mathrm{MBL}$, where the critical plane approach predicts $12.9 \%$ in the low-cycle fatigue regime, while the traditional SN approach predicts only $7.2 \%$. The result is that the critical plane approach predicts almost twice the proportion of low-cycle fatigue than the traditional $\mathrm{SN}$ approach predicts. 


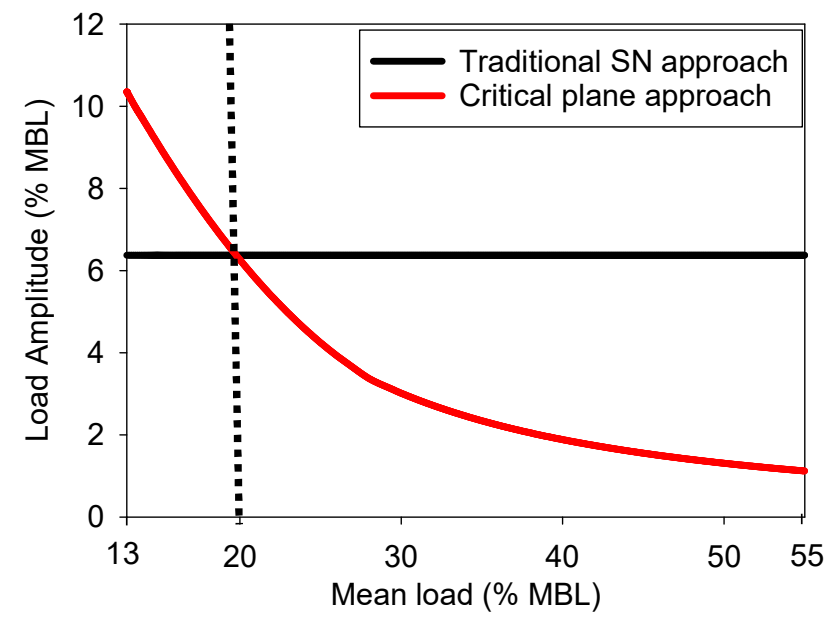

Fig. 11. The separation line between high-cycle and low-cycle fatigue predictions for the traditional SN approach and the critical plane approach.

The results of the two case studies show the importance of considering low-cycle fatigue contributions in mooring failures. For example, mooring chains are subjected to $5.33 \times 10^{5}$ loading cycles at three years of operation, assuming total individual loading cycles of 1828 for every 3 hours of operation based on the case study. The critical plane approach comes closer to explaining why some mooring chain failures are reported as occurring in the first three years [1] [3]. This is because it predicts a higher proportion of low-cycle fatigue loading cycles during this period than the traditional SN approach, as demonstrated in Fig. 8 and Fig. 11. The pre-tension affects the mean loads as the higher the pre-tension, the higher the mean loads, and mooring systems in the field normally have a pre-tension between $10 \%$ and $20 \%$ MBL [40], where the pre-tension in the case study is $17 \%$ MBL. As the mooring chain failures occurred in harsh sea environments [1] [3], it is hypothesised that the pre-tension of the greatest loaded line increases with the mean loads, which leads to an increase in the proportion of low-cycle fatigue causing the reported early failures in the first three years of operation. This is also reflected in the seastates study, where the more severe the sea-states, the higher the proportion of time the mean load is above $20 \%$ MBL and the more accurate the critical plane approach becomes. This implies that in calm sea regions, the traditional SN approach is conservative, but in harsh sea regions, the traditional SN approach can be nonconservative, which is where the most early failures have occurred [1] [3].

One common recommendation in industry is to increase the minimum breaking load by increasing the chain diameter, which will decrease the cyclic load magnitude in terms of \% MBL experienced; however, this can increase the applied pre-tension to above $20 \%$ MBL because the larger the diameter, the heavier the mooring line will be. Another recommendation is to lower the pre-tension by making the mooring line longer; however, this may reduce the mooring line damping, increasing the motions and decreasing the fatigue life [48] [49]. Increasing the steel grade to achieve a greater minimum breaking load could be a viable solution to reduce the cyclic load magnitude in terms of \% MBL; however, this is not a simple substitution and should be adopted with caution since the higher the strength of steels, the more prone to hydrogen-assisted cracking they may be, bringing in additional failure modes, not accounted for in the fatigue evaluation [5] [50]. It should also be noted that the chain can also be corroded or subject to wear, which may reduce the chain fatigue capacity by promoting more detrimental mean load effects, leading to a decrease in the $20 \%$ MBL mean load threshold and an increase in the proportion of low-cycle fatigue.

\section{Conclusion}

This paper investigates how fatigue damage prediction changes with a more accurate representation of the lowcycle fatigue regime, using a strain-based critical plane approach, under stochastic tension loading in service for intact mooring chains. The critical plane approach is developed based on the multiaxial stress-strain conditions at the hotspot and this is correlated with the fatigue life derived from tests taken from the mooring standards. The fatigue damage accumulation predicted by the critical plane approach is significantly higher than the traditional 
SN approach, $75 \%$ on average for all of the material models considered here. It is found in this case study that the mean load effect is detrimental when it is above $20 \%$ of the minimum breaking load, shown to be a high proportion of sea-states 4-9. In addition, it demonstrates that increasing the diameter of the mooring chain may exacerbate this problem, indicating that more explicitly tailored chain design is needed to reduce this issue. The effect of the cyclic plasticity is limited as the mechanisms are only applied when the tension load exceeds $70 \%$ of the minimum breaking load due to the strain hardening from the proof load application during the first cycle. The critical plane approach predicts higher proportions of low-cycle fatigue than the traditional SN approach in the mooring line loading when the mean load is above $20 \%$ of the minimum breaking load, with the difference being dependent on the mean loads and the load amplitudes witnessed in operation. The traditional SN approach is conservative when the mean load is below $20 \%$ of the minimum breaking load, but after this, it is nonconservative, which is observed in harsh environments where the majority of mooring chain failures were witnessed. The low-cycle fatigue analysis explains why current fatigue assessment in mooring chain applications is non-conservative and demonstrates that the critical plane approach should be accounted for in mooring line design.

\section{Declaration of competing interest}

None.

\section{Acknowledgement}

The authors gratefully acknowledge the funding by the Indonesia Endowment Fund for Education (LPDP) and the support of the Lloyd's Register Foundation (LRF). The authors also acknowledge the support of the University of Southampton for access to its IRIDIS5 High-Performance Computing Facility.

\section{Appendix A}

Table A.1 presents the resultant $S W T$ damage parameters, according to Eq. (1), and the correlated number of cycles to failure from the fatigue life predictions based on the SN curve of DNVGL-OS-E301 [6] under different load amplitudes, i.e. from $1 \%$ to $19 \% \mathrm{MBL}$.

Table A.1

Resultant SWT fatigue damage parameters for different amplitudes and the correlated number of cycles to failure.

\begin{tabular}{ccccccccccccc}
\hline & $\begin{array}{c}\text { No. of } \\
\text { Amplitude } \\
\text { (\% MBL) }\end{array}$ & $\begin{array}{c}\text { cycles to } \\
\text { failure }\end{array}$ & $\begin{array}{c}\sigma_{\mathrm{n}, \max } \\
(\mathrm{MPa})\end{array}$ & $\Delta \varepsilon_{\mathrm{n}}$ & $S W T$ & $\begin{array}{c}\sigma_{\mathrm{n}, \max } \\
(\mathrm{MPa})\end{array}$ & $\Delta \varepsilon_{\mathrm{n}}$ & $S W T$ & $\begin{array}{c}\sigma_{\mathrm{n}, \max } \\
(\mathrm{MPa})\end{array}$ & $\Delta \varepsilon_{\mathrm{n}}$ & $S W T$ \\
\hline 19 & 3778 & 420.826 & 0.003694 & 0.77716 & 350.278 & 0.003359 & 0.58822 & 362.488 & 0.003313 & 0.60048 \\
17 & 5275 & 381.147 & 0.003304 & 0.62959 & 314.186 & 0.003005 & 0.47205 & 327.542 & 0.002962 & 0.48516 \\
15 & 7679 & 341.579 & 0.002915 & 0.49791 & 277.977 & 0.002651 & 0.36851 & 291.943 & 0.002613 & 0.38149 \\
13 & 11796 & 301.763 & 0.002526 & 0.38116 & 241.775 & 0.002298 & 0.27776 & 256.228 & 0.002265 & 0.29014 \\
11 & 19471 & 262.004 & 0.002139 & 0.28024 & 205.567 & 0.001944 & 0.19983 & 220.473 & 0.001916 & 0.21125 \\
9 & 35550 & 222.164 & 0.001749 & 0.19427 & 169.330 & 0.001591 & 0.13467 & 184.743 & 0.001568 & 0.14483 \\
7 & 75556 & 182.396 & 0.001361 & 0.12411 & 133.120 & 0.001237 & 0.08234 & 149.016 & 0.001219 & 0.09085 \\
5 & 207326 & 142.544 & 0.000972 & 0.06924 & 96.827 & 0.000884 & 0.04278 & 113.244 & 0.000871 & 0.04931 \\
3 & 959844 & 102.589 & 0.000583 & 0.02992 & 60.522 & 0.000530 & 0.01605 & 77.445 & 0.000523 & 0.02023 \\
1 & 25915776 & 62.673 & 0.000194 & 0.00609 & 24.188 & 0.000177 & 0.00229 & 41.600 & 0.000174 & 0.00362 \\
\hline
\end{tabular}

The resultant $S W T$ damage parameters under different load amplitudes, shown in Table A.1, are used to calibrate the parameters of the fitted curves based on the general formula of Eq. (2) in order to interpolate the number of cycles to failure from the corresponding SWT damage parameters during fatigue loading. Table A.2 provides 
details regarding the calibration of parameters of the fitted curves. Good-match fitting is needed to give an accurate fitted curve between the predicted $S W T$ damage parameters across a range of the number of cycles to failure. Therefore, in order to generate a good fit to the data, the fitting curves are separated into lower and upper fitting curves, where the lower fitting curves are used when the number of cycles to failure is below 75556, and the upper fitting curves are used when the number of cycles to failure above 75556. It is seen that using the upper and lower fitting curves, good fits are obtained with R-squared, $R^{2}$, above $99.9 \%$.

Table A. 2

Details of parameters of fitted curves for predicted $S W T$ fatigue damage parameters.

\begin{tabular}{ccccccc}
\hline \multirow{2}{*}{ Material } & \multicolumn{4}{c}{ Material constants based on Eq. (2) } & \multirow{2}{*}{$R^{2}$} \\
\cline { 2 - 6 } & & $A 1$ & $a 1$ & $A 2$ & $a 2$ & $R^{2}$ \\
\hline \multirow{2}{*}{ Mono-Rampi } & Upper fittings & 60.05743 & -0.612928 & 60.05743 & -0.612928 & $99.989 \%$ \\
\cline { 2 - 7 } & Lower fittings & 15.32255 & -0.500088 & 15.32255 & -0.500088 & $99.904 \%$ \\
\hline \multirow{2}{*}{ Cyclic-Rampi } & Upper fittings & 65.53905 & -0.656548 & 65.53905 & -0.656548 & $99.999 \%$ \\
\cline { 2 - 7 } & Lower fittings & 33.80939 & -0.60351 & 33.80939 & -0.60351 & $99.961 \%$ \\
\hline \multirow{2}{*}{ Cyclic-Zarandi } & Upper fittings & 54.05119 & -0.631039 & 54.05119 & -0.631039 & $99.995 \%$ \\
\cline { 2 - 7 } & Lower fittings & 17.35095 & -0.537771 & 17.35095 & -0.537771 & $99.930 \%$ \\
\hline
\end{tabular}

\section{Appendix B}

Table B.1 presents the scatter diagram in the North Sea where the joint occurrence probabilities of significant wave height, $H_{\mathrm{s}}$, and up-crossing wave period, $T_{\mathrm{z}}$, are presented in the wave scatter diagram. The scatter diagram, consisting of 197 original sea-states, is partitioned into nine representative sea-state blocks to estimate the long-term structural fatigue damage accumulated by variable wave conditions. A mooring line simulation is performed at each sea-state block.

Table B.1

The wave scatter diagram in the North Sea [47].

\begin{tabular}{|c|c|c|c|c|c|c|c|c|c|c|c|c|c|c|c|c|c|c|}
\hline \multirow{2}{*}{$\begin{array}{c}H_{\mathrm{s}} \\
(\mathrm{m})\end{array}$} & \multicolumn{18}{|c|}{$T_{\mathrm{z}}(\mathrm{s})$} \\
\hline & 1.5 & 2.5 & 3.5 & 4.5 & 5.5 & 6.5 & 7.5 & 8.5 & 9.5 & 10.5 & 11.5 & 12.5 & 13.5 & 14.5 & 15.5 & 16.5 & 17.5 & 18.5 \\
\hline 0.5 & 0 & 0 & 13 & 1337 & 8656 & 11860 & 6342 & 1863 & 369 & 56 & 7 & 1 & 0 & 0 & 0 & 0 & 0 & 0 \\
\hline 1.5 & 0 & 0 & 0 & 293 & 9860 & $49760_{1}$ & 77380 & 55697 & 23757 & 7035 & 1607 & 2305 & 51 & 8 & 1 & 0 & 0 & 0 \\
\hline 2.5 & 0 & 0 & 0 & 22 & 1975 & 21588 & 62300 & 74495 & 48604 & 20660 & 6445 & 1602 & 337 & 63 & 11 & 2 & 0 & 0 \\
\hline 3.5 & 0 & 0 & 0 & 2 & 349 & 6955 & 32265 & 56750 & 50991 & 28380 & 11141 & 3377 & 843 & 182 & 35 & 6 & 1 & 0 \\
\hline 4.5 & 0 & 0 & 0 & 0 & 60 & 1961 & 13543 & 32885 & 38575 & 26855 & 12752 & 4551 & 1309 & 319 & 69 & 13 & 2 & 0 \\
\hline 5.5 & 0 & 0 & 0 & 0 & 10 & 510 & 4984 & $16029^{3}$ & 23727 & 20083 & 11260 & 4636 & $1509^{4}$ & 410 & 97 & 21 & 4 & 1 \\
\hline 6.5 & 0 & 0 & 0 & 0 & 2 & 126 & 1670 & 6903 & 12579 & 12686 & 8259 & 3868 & 1408 & 422 & 109 & 25 & 5 & 1 \\
\hline 7.5 & 0 & 0 & 0 & 0 & 0 & 30 & 521 & 2701 & 5944 & 7032 & 5249 & 2767 & 1117 & 367 & 102 & 25 & 6 & 1 \\
\hline 8.5 & 0 & 0 & 0 & 0 & 0 & 7 & 154 & ${ }_{979} \mathbf{5}$ & 2559 & 3506 & 2969 & 1746 & 7766 & 277 & 84 & 22 & 5 & 1 \\
\hline 9.5 & 0 & 0 & 0 & 0 & 0 & 2 & 43 & 332 & 1019 & 1599 & 1522 & 992 & 483 & 187 & 61 & 17 & 4 & 1 \\
\hline 10.5 & 0 & 0 & 0 & 0 & 0 & 0 & 12 & 107 & 379 & 675 & 717 & 515 & 273 & 114 & 40 & 12 & 3 & 1 \\
\hline 11.5 & 0 & 0 & 0 & 0 & 0 & 0 & 3 & $33^{7}$ & 133 & 266 & 314 & 247 & 1428 & 64 & 24 & 7 & 2 & 1 \\
\hline 12.5 & 0 & 0 & 0 & 0 & 0 & 0 & 1 & 10 & 44 & 99 & 128 & 110 & 68 & 33 & 13 & 4 & 1 & 0 \\
\hline 13.5 & 0 & 0 & 0 & 0 & 0 & 0 & 0 & 3 & 14 & 35 & 50 & 46 & 31 & 16 & 7 & 2 & 1 & 0 \\
\hline 14.5 & 0 & 0 & 0 & 0 & 0 & 0 & 0 & 1 & 4 & 12 & ${ }_{18}^{9}$ & 18 & 13 & 7 & 3 & 1 & 0 & 0 \\
\hline 15.5 & 0 & 0 & 0 & 0 & 0 & 0 & 0 & 0 & 1 & 4 & 6 & 7 & 5 & 3 & 1 & 1 & 0 & 0 \\
\hline 16.5 & 0 & 0 & 0 & 0 & 0 & 0 & 0 & 0 & 0 & 1 & 2 & 2 & 2 & 1 & 1 & 0 & 0 & 0 \\
\hline
\end{tabular}




\section{References}

[1] E. Fontaine, A. Kilner, C. Carra, D. Washington, K. Ma, and A. Phadke, "Industry survey of past failures, pre-emptive replacements and reported degradation for mooring systems of floating production units," in Proceeding of Offshore Technology Conference OTC-25273, 2014, p. 14.

[2] C. Barrera, R. Guanche, and I. J. Losada, "Experimental modelling of mooring systems for floating marine energy concepts," Mar. Struct., vol. 63, pp. 153-180, 2019.

[3] K. Ma, A. Duggal, P. Smedley, D. L'Hostis, and H. Shu, “A Historical Review on Integrity Issues of Permanent Mooring Systems," in Proceedings of Offshore Technology Conference OTC-24025, 2013, p. 14.

[4] S. Majhi and R. D. Souza, "Application of Lessons Learned From Field Experience to Design, Installation and Maintenance of FPS Moorings," in Proceedings of Offshore Technology Conference OTC-24181, 2013, p. 15.

[5] A. Kvitrud, "Lessons Learned From Norwegian Mooring Line Failures 2010-2013," in ASME $201433 \mathrm{rd}$ International Conference on Ocean, Offshore and Arctic Engineering OMAE2014-23095, 2014, p. 10.

[6] Det Norske Veritas, "Offshore Standard DNVGL-OS-E301 Position Mooring," DNV, Høvik, Norway, 2013. [Online]. Available: https://rules.dnvgl.com/docs/pdf/DNV/codes/docs/2013-10/OS-E301.pdf. [Accessed: 19-Jul-2018].

[7] Ø. Gabrielsen, K. Larsen, O. Dalane, H. Lie, and S. Reinholdtsen, "Mean Load Impact on Mooring Chain Fatigue Capacity - Lessons Learned from Full Scale Fatigue Testing of Used Chains," in ASME 2019 38th International Conference on Ocean, Offshore and Arctic Engineering OMAE2019-95083, 2019, p. 8.

[8] Ø. Gabrielsen, K. Larsen, and S. A. Reinholdtsen, "Fatigue Testing of Used Mooring Chain," in ASME 2017 36th International Conference on Ocean, Offshore and Arctic Engineering OMAE2017-61382, 2017, p. 11.

[9] Y. Zhang and P. Smedley, "Fatigue Performance of High Strength and Large Diameter," in ASME 2019 38th International Conference on Ocean, Offshore and Arctic Engineering OMAE2019-95984, 2019, p. 11.

[10] S. Suresh, Fatigue of Materials Book, 2nd ed. New York: Cambridge University Press, 1998.

[11] I. M. Perez, P. Bastid, A. Constantinescu, and V. Venugopal, "Multiaxial Fatigue Analysis of Mooring Chain Links Under Tension Loading: Influence of Mean Load and Simplified Assessment," in ASME 2018 37th International Conference on Ocean, Offshore and Arctic Engineering OMAE2018-77552, 2018, p. 12.

[12] P. Pacheco, P. Kenedi, J. Jorge, M. Savi, and H. Santos, "Finite Element Residual Stress Analysis Applied to Offshore Studless Chain Links," in ASME 2004 23rd International Conference on Offshore Mechanics and Arctic Engineering OMAE2004-51508, 2004, p. 10.

[13] X. Xue, N. Z. Chen, Y. Wu, Y. Xiong, and Y. Guo, "Mooring system fatigue analysis for a semisubmersible," Ocean Eng., vol. 156, pp. 550-563, 2018.

[14] P. Pacheco, P. Kenedi, J. Jorge, and A. Paiva, "Analysis of the Influence of Mechanical Properties on the Residual Stress in Offshore Chain Links Using the Finite Element Method," in ASME 2003 22nd International Conference on Offshore Mechanics and Arctic Engineering OMAE2003-37205, 2003, p. 10.

[15] T. Palin-Luc, R. Pérez-Mora, C. Bathias, G. Domínguez, P. C. Paris, and J. L. Arana, "Fatigue crack initiation and growth on a steel in the very high cycle regime with sea water corrosion," Eng. Fract. Mech., vol. 77, no. 11, pp. 1953-1962, 2010.

[16] R. Pérez-Mora, T. Palin-Luc, C. Bathias, and P. C. Paris, "Very high cycle fatigue of a high strength steel under sea water corrosion: A strong corrosion and mechanical damage coupling," Int. J. Fatigue, vol. 74, pp. 156-165, 2015.

[17] M. Benedetti, V. Fontanari, and M. Bandini, "A simplified and fast method to predict plain and notch fatigue of shot peened high-strength aluminium alloys under reverse bending," Surf. Coatings Technol., vol. 243, pp. 2-9, 2014.

[18] M. Benedetti, V. Fontanari, M. Bandini, and D. Taylor, "Multiaxial fatigue resistance of shot peened highstrength aluminum alloys," Int. J. Fatigue, vol. 61, pp. 271-282, 2014.

[19] M. Benedetti, V. Fontanari, C. Santus, and M. Bandini, "Notch fatigue behaviour of shot peened highstrength aluminium alloys: Experiments and predictions using a critical distance method," Int. J. Fatigue, vol. 32, no. 10, pp. 1600-1611, 2010.

[20] J. Liu and M. Pang, "Fatigue life prediction of shot-peened steel," Int. J. Fatigue, vol. 43, pp. 134-141, 2012.

[21] A. Fatemi and N. Shamsaei, "Multiaxial fatigue: An overview and some approximation models for life 
estimation," Int. J. Fatigue, vol. 33, no. 8, pp. 948-958, 2011.

[22] E. P. Zarandi and B. H. Skallerud, "Cyclic behavior and strain energy-based fatigue damage analysis of mooring chains high strength steel," Mar. Struct., vol. 70, p. 18, 2020.

[23] E. P. Zarandi and B. H. Skallerud, "Experimental and numerical study of mooring chain residual stresses and implications for fatigue life," Int. J. Fatigue, vol. 135, 2020.

[24] B. You and S. Lee, "A critical review on multiaxial fatigue assessments of metals," Int. J. Fatigue, vol. 18, no. 4, pp. 235-244, 1996.

[25] Y. Jiang, O. Hertel, and M. Vormwald, "An experimental evaluation of three critical plane multiaxial fatigue criteria," Int. J. Fatigue, vol. 29, no. 8, pp. 1490-1502, 2007.

[26] C. You, M. Achintha, K. Soady, and P. Reed, "Low cycle fatigue life prediction in shot-peened components of different geometries - part II: life prediction," Fatigue Fract. Eng. Mater. Struct., vol. 40, no. 5, pp. 749-760, May 2017.

[27] K. S. Kim and J. C. Park, "Shear strain based multiaxial fatigue parameters applied to variable amplitude loading," Int. J. Fatigue, vol. 21, no. 5, pp. 475-483, 1999.

[28] C. Han, X. Chen, and K. S. Kim, "Evaluation of multiaxial fatigue criteria under irregular loading," Int. J. Fatigue, vol. 24, no. 9, pp. 913-922, 2002.

[29] A. Carpinteri, A. Spagnoli, and S. Vantadori, "Multiaxial fatigue life estimation in welded joints using the critical plane approach," Int. J. Fatigue, vol. 31, no. 1, pp. 188-196, 2009.

[30] IACS (International Association of Classification Societies), "W22 Offshore Mooring Chain," International Association of Classification Societies, 2016. [Online]. Available: http://www.iacs.org.uk/publications/unified-requirements/ur-w/ur-w22-rev6-cln/. [Accessed: 04-Feb2019].

[31] J. Fernández, W. Storesund, and J. Navas, "Fatigue Performance of Grade R4 and R5 Mooring Chains in Seawater," in ASME 2014 33nd International Conference on Offshore Mechanics and Arctic Engineering OMAE2014-23491, 2014, p. 6.

[32] G. M. Gemilang, P. A. S. Reed, and A. J. Sobey, "(Manuscript subjected to minor revision) Selection of appropriate numerical models for modelling the operating stresses in mooring chains," Mar. Struct., 2020.

[33] Dassault Systèmes Simulia Corp., “Abaqus Analysis User's Guide 6.13,” ABAQUS, Inc., 2013. [Online]. Available:

http://dsk.ippt.pan.pl/docs/abaqus/v6.13/books/usb/default.htm?startat=pt09ch36s03aus145.html. [Accessed: 19-Feb-2020].

[34] L. Rampi, A. Bignonnet, C. Le Cunff, F. Bourgin, and P. Vargas, "Chain Out of Plane Bending (OPB) Fatigue Joint Industry Project (JIP) FEA Results and Multiaxiality Study Results,” in ASME 2016 35th International Conference on Ocean, Offshore and Arctic Engineering OMAE2016-54198, 2016, p. 15.

[35] Det Norske Veritas, "DNV-OS-E302 Offshore Mooring Chain," DNV, Høvik, Norway., 2015. [Online]. Available: https://rules.dnvgl.com/docs/pdf/DNV/codes/docs/2009-10/OS-E302.pdf. [Accessed: 19-Jul2018].

[36] J. L. Chaboche, "Time-independent constitutive theories for cyclic plasticity," Int. J. Plast., vol. 2, no. 2, pp. 149-188, 1986.

[37] C. Lee, K. Chang, and V. Van, "Numerical investigation on the ratcheting behavior of pressurized stainless steel pipes under cyclic in-plane bending," Mar. Struct., vol. 49, pp. 224-238, 2016.

[38] K. N. Smith, T. Topper, and P. Watson, "A stress-strain function for the fatigue of metals (stress-strain function for metal fatigue including mean stress effect)," J. Mater., vol. 5, pp. 767-778, Jan. 1970.

[39] D. Socie, “Multiaxial Fatigue Damage Models,” J. Eng. Mater. Technol., vol. 109, no. 4, pp. 293-298, Oct. 1987.

[40] K. Ma, Ø. Gabrielsen, Z. Li, D. Baker, A. Yao, and P. Vargas, "Fatigue Tests on Corroded Mooring Chains Retrieved From Various Fields in Offshore West Africa and the North Sea," in ASME 2019 38th International Conference on Offshore Mechanics and Arctic Engineering OMAE2019-95618, 2019, p. 17.

[41] Flexcom Software Documentation, "Flexcom Version 8.10.2 Examples Manual." Galway: Wood Group Kenny, 2019.

[42] Z. Gao and T. Moan, "Wave-induced fatigue damage of mooring chain under combined non-Gaussian low and wave frequency loads," in ASME 2006 25th International Conference on Ocean, Offshore and Arctic Engineering OMAE2006-92389, 2006, p. 7.

[43] American Petroleum Institute, "API RP 2SK: Recommended Practice for Design and Analysis of Stationkeeping Systems for Floating Structures," Washington, D. C., 2005.

[44] M. Matsuishi and T. Endo, "Fatigue of metals subjected to varying stress," Japan Soc. Mech. Eng. 
Fukuoka, Japan, vol. 68, no. 2, pp. 37-40, 1968.

[45] G. Marsh, C. Wignall, P. R. Thies, N. Barltrop, A. Incecik, and V. Venugopal, "Review and application of Rainflow residue processing techniques for accurate fatigue damage estimation," Int. J. Fatigue, vol. 82, pp. 757-765, 2016.

[46] M. A. Miner, "Cumulative damage in fatigue," J. Appl. Mech., vol. 12, no. American Society of Mechanical Engineers-Journal of Applied Mechanics, pp. A159-A164, 1945.

[47] X. Song and S. Wang, "A novel spectral moments equivalence based lumping block method for efficient estimation of offshore structural fatigue damage," Int. J. Fatigue, vol. 118, pp. 162-175, 2019.

[48] Y. Yang, J. X. Chen, and S. Huang, "Mooring line damping due to low-frequency superimposed with wave-frequency random line top end motion," Ocean Eng., vol. 112, pp. 243-252, 2016.

[49] Y. Wu, T. Wang, Ø. Eide, and K. Haverty, "Governing factors and locations of fatigue damage on mooring lines of floating structures,” Ocean Eng., vol. 96, pp. 109-124, 2015.

[50] L. Coudreuse, C. Renaudin, P. Bocquet, and L. Cadiou, "Evaluation of hydrogen assisted cracking resistance of high strength Jack-up steels," Mar. Struct., vol. 10, no. 2, pp. 85-106, 1997. 